\title{
La biblioteca oriental de Francisco de Herrera Maldonado
}

\author{
Marcela Londoño Rendón \\ Universitat Autònoma de Barcelona \\ AngelaMarcela.Londono@uab.cat
}

Fecha de recepción: 17/12/2010, Fecha de publicación: 20/12/2010

<URL: http://www.studiaaurea.com/articulo.php?id=158>

\begin{abstract}
Resumen
La imagen europea de oriente es un proceso de construcción textual que se inició después de los primeros viajes portugueses a otros continentes. En las primeras décadas del siglo XVII ya se habían escrito las obras paradigmáticas que determinarían durante siglos la percepción occidental de China y Japón. Este artículo analiza el carácter de los textos que informaban sobre el tema a la Europa culta, a través del catálogo bibliográfico que recogió Francisco de Herrera Maldonado en su traducción de un texto portugués capital en la época de los descubrimientos. Su estudio nos remite inevitablemente al papel fundamental que cumplieron los escritores de las diferentes órdenes religiosas en la tarea de creación de imágenes del otro.
\end{abstract}

\section{Palabras clave}

Viajes a oriente, Francisco de Herrera Maldonado, Mendes Pinto, órdenes religiosas, catálogo bibliográfico, relaciones intertextuales.

\begin{abstract}
Francisco de Herrera Maldonado and the Orientalist Bookshelf in Early Modern Europe The European view of the East is built upon a literary tradition that began to take form after the first Portuguese travels to other continents. Some of the works written in the first decades of the seventeenth century would shape for centuries the Western outlook of China and Japan. This article studies this textual tradition and its relevance for Early Modern European educated circles by examining a compilation of works devoted to Eastern lands and peoples made by Francisco de Herrera Maldonado. Herrera published this catalogue of books in the prologue of the Spanish translation of Mendes Pinto's Peregrinaçam, one of the most important contemporary Portuguese historical accounts of discoveries. Herrera's orientalist library reveals, among other things, the crucial role played by religious orders in the making of the Western images of the others and especially of others from the East.
\end{abstract}

Key words

Expeditions to East, Francisco de Herrera Maldonado, Mendes Pinto, orders religious, bibliographic catalogue, intertextual relationship. 
El orientalismo, que es una disciplina filológica e historiográfica, se ha estudiado como fenómeno cultural de los siglos XIX y XX, a través, sobre todo, de materiales británicos y franceses. Ahora bien, la construcción en la primera modernidad de la imagen del oriente lejano - y, en particular, del reino de la China - fue una tarea textual portuguesa e hispánica. El Catálogo de los autores que han escrito de las Indias orientales, Japón y China y de sus situaciones, navegación y conquistas, que reunió en 1620 el canónigo español Francisco de Herrera Maldonado, se imprimió con los materiales preliminares de su traducción más famosa, la de la Peregrinaçam de Fernão Mendes Pinto, allegando las autoridades más relevantes en materia oriental tras un siglo de viajes. ${ }^{1} \mathrm{La}$ presentación y el comentario de su contenido constituyen los dos objetivos centrales de este artículo, cuyo propósito es el de reconstruir la biblioteca oriental hispano-portuguesa (y, por ende, europea) en los primeros ańos del siglo xvir: sólo así podrá examinarse la orientación ideológica de los textos que formaron la idea y representación de China para los lectores europeos de los siglos áureos, percibir el impacto de cada una de las órdenes religiosas que participaron en el intento de expandir la religión cristiana en los territorios del lejano oriente y establecer el vínculo de los textos más importantes con viajeros y misioneros precisos. Para comprender el significado de este documento conviene comenzar con el comentario de la obra a la que acompañaba y con los propósitos para los que fue escrito.

La Historia oriental de las peregrinaciones de Fernán Méndez Pinto, impresa en Madrid en 1620 fue el título que recibió en castellano la Peregrinaçam de Fernão Mendes Pinto que se había publicado por primera vez en Lisboa apenas seis años antes. La obra narra el largo y accidentado viaje de su autor por territorios orientales en el período comprendido entre 1537 y 1558 . El texto va más allá del relato autobiográfico, pues reúne también características propias de otros

1. Historia oriental de las peregrinaciones de Fernán Méndez Pinto, portugvés, adonde se escriven mvchas y muy estrañas cosas que vio, y oyó en los Reynos de la China, Tartaria, Sornao, que vulgarmente se llama Siam, Calaminam, Peguu, Martauan, y otros muchos de aquellas partes orientales, de que en estas nuestro Occidente nay muy poca, o ninguna noticia. Casos famosos, acontecimientos admirables, leyes, govierno, trages, Religión y costumbres de aquellos Gentiles de Asia.[Texto impreso]/ traduzido de portugves en castellano por el licenciado Francisco de Herrera Maldonado canónigo de la Santa Iglesia real de Arbas, [S.1]: [s.n.], 1620 (Al fin: Madrid): Viuda de Luis Sánchez.

Peregrinaçam de Fernam Mendez Pinto em que da conta de muytas e muyto estranhas cousas que vio \& ounio no reyno da China, no da Tartaria, no do Sornau, que vulgarmente se chama Siäo, no do Calaminhan, no de Pegù, no de Martauão, \& em outros muytos reynos \& senhorios das partes Orientais, de que nestas nossas do Occidente ha muyto pouca ou nenhu[m]a noticia. E tambem da conta de muytos casos particulares que aconteceräo assi a elle como a outras pessoas. E no fin Della brevemente de algunas cousas, \& da morte do Santo Padre Francisco Xavier, unica luz \& resplandor daquellas partes do Oriente, \& Reitor nellas universal da Companhia de Iesus. Escrita pelo mesmo Fernáo Mendez Pinto. Dirigido à Catholica Real Magestade del Rey dom Felippe o III. Deste nome nosso Senhor. Lisboa: Pedro Crasbeeck: a custa de Belchior de Faria, 1614. 
géneros, como la novela de aventuras o la crónica. La excepcional extensión de la obra, que el primer editor distribuyó en doscientos veintiséis capítulos, permitió al autor utilizar elementos muy diversos en su composición. A grandes rasgos, es posible reconocer seis bloques temáticos marcados por el encuentro con un personaje importante que se convierte temporalmente en protagonista de la historia - Antonio de Faria y Francisco Javier - o por la estancia en lugares determinados. La primera persona del narrador, que está presente en todos los momentos del relato, cede el lugar preeminente a una tercera persona del singular o se integra en un nosotros según la temática del bloque. ${ }^{2}$ Desde el capítulo I hasta el XXXVIII el personaje Méndez Pinto nos cuenta en primera persona las circunstancias en las que inicia su «peregrinación» desde Portugal, pasando por la India, el reino de los Batas y Arabia, hasta el reino de Pan (Pão). En la segunda parte el foco de la narración se centra en la tercera persona de Antonio de Faria a quien el personaje Pinto sirve en los capítulos XXXVI a LXXIX. ${ }^{3}$ Entre los capítulos LXXX y CXLIII, el narrador colectivo nosotros cuenta el recorrido por China, Tartaria, Siam y las islas de los lequios y Tanixumá. En el cuarto bloque, aparece como un personaje más que acompaña al rey de los Bramas en un recorrido por Pegu, el desconocido Calamiñam y las tierras de Sonda, y que continúa con este hasta tierras de Siam y Birmania (CXLIV-CXCIX). ${ }^{4}$ En el quinto bloque, en fin, entre los capítulos CC-CCXXVI, la primera persona del narrador vuelve a conceder mayor importancia a otros personajes, sobre todo al padre Francisco Javier, pero también a su sucesor Melchor Núnez, durante el recorrido por Malaca, Japón y los mares de la China hasta el regreso a Goa. En la última parte del capítulo XXVI la primera persona del narrador principal cuenta el regreso a Portugal y hace algunas reflexiones sobre la experiencia vivida y el poco reconocimiento de sus trabajos.

La Peregrinaçam es una obra fundamental en la historia de la literatura portuguesa, que se leyó en toda Europa a lo largo del siglo xvir y a la que la crítica del siglo xx ha dispensado una singular atención. Todavía hoy, sin embargo, persisten las incógnitas que rodearon la vida de su autor. ${ }^{5}$ La única información

2. Historia oriental (2009). Todas las referencias de la obra en castellano pertenecen a esta edición. Para un comentario más detallado de la estructura de la obra véase Pinto Correia (1979, pp. 56-57).

3. Algunos estudiosos de la obra, sobre todo aquellos que defienden su interpretación como una sátira (Catz, 1978) o como una sátira picaresca (Saraiva, 1958) han querido ver en Antonio de Faria un personaje de ficción creado por el autor para realizar una elaborada crítica contra el imperialismo europeo y la ideología de cruzada. En 1971 Eugénio Andrea da Cun- ha e Freitas publica el testamento de Antonio de Faria en los Anais da Académia Portuguesa da História con lo que desautoriza la hipótesis, aunque Catz parece no haberlo tenido en cuenta y en 1978 publica un trabajo en el que la propone de nuevo. Cf. Almeida (1989).

4. Calamiñam: tal vez Laos o Tibet según Roque de Oliveira (2003, p. 1315).

5. Cristóvão Aires $(1904,1906)$ y Jordão de Freitas $(1905,1907)$ son los autores que inician la investigación en torno a la vida de Pinto. Muchos investigadores realizaron trabajos sobre el tema, entre algunos de los más impor- 
de la que disponemos es la que proporciona él mismo en su obra: por ella sabemos que nació en Montemor-o-Velho entre 1509 y 1511, en una familia de escasos recursos, y que llega a Lisboa de la mano de un tío en 1521. En 1526 se encuentra sirviendo "a una señora de generación ilustre y parientes nobles», y un año y medio después tiene que huir para salvar su vida, sin mencionar cuál es el motivo de la fuga. Consigue embarcar en la Alfama en una carabela que se dirige a Setúbal, pero la nave es atacada por cosarios franceses que la saquean y toman prisioneros a algunos tripulantes con la supuesta intención de venderlos como esclavos en Larache. Finalmente Mendes Pinto y otros compañeros, hambrientos, desnudos y heridos por los azotes, son abandonados en la playa de Melides desde donde llega con dificultad a Setúbal. Allí sirve durante cuatro años en casa de Francisco Faria de la Orden de Santiago con cuyo maestro trabajará durante un año y medio, pero la escasez de ganancias de este servicio lo llevan a embarcarse hacia la India el 11 de marzo de 1537, viaje en el que empeñará casi veinte años de su vida, y del que sólo regresará en $1558 .{ }^{6}$

Además de esto, se sabe que de 1554 a 1556 perteneció a la Compañía de Jesus. Se desconocen los motivos de su pronta renuncia, tema que ha ocupado a los investigadores durante mucho tiempo, sobre todo por las consecuencias perniciosas que el abandono de los hábitos pudo causar a la divulgación de su obra. Los jesuitas podrían haber intervenido los contenidos y/o haber silenciado algunas cartas escritas por Pinto o fragmentos de cartas de otros hermanos en los que aparecía citado. ${ }^{7}$ De su corta experiencia como ignaciano nos quedan tan sólo dos cartas que constituyen el único testimonio escrito por el autor durante su periplo por Oriente. ${ }^{8}$

No menos interesantes resultan las circunstancias de publicación y difusión del texto, al parecer compuesto entre 1569 y 1580, pero que sólo salió a la luz en 1614, más de tres décadas después de la muerte de Mendes Pinto en 1583. Los motivos de este retraso nunca han sido aclarados. Rebecca Catz sostiene que el autor temía posibles represalias de la Inquisición debido al carácter crítico de algunos apartados de su obra; por su parte, Collis cree que la extensión del manuscrito y el imperfecto estado en el que el autor lo había dejado al morir demoraron considerablemente la labor de corrección. ${ }^{9}$ Nunca lo sabremos con

tantes se cuentan los de Cortesão (1943), Saraiva (1958) y Catz (1978).

6. Cf. Almeida (1989).

7. Lara Vilà (2009) «Estudio preliminar»y para un análisis conciso de la obra véase Roque de Oliveira (2003: pp. 1307-1343).

8. Carta dum Irmão da Companhia de Jesus de Malaca pera os padres e irmáos da Companhia em Portugal de 1554 y la Cópia de uma carta (de um irmáo da Companhia) que escreveo [de] Malaca (aliás Macau) ao Reitor do Colégio de Goa de 1555 anos, 20 de Novembro en Saraiva (1984). Durante un tiempo se atribuyó también a Pinto la Enformação de algumas cousas acerca dos costumes e leis do reino da China, que hum homem honrado, que la esteve catico seis anos contou no colegio de Malaca ao P. Mestre Belchior [1554] porque llegó a Portugal junto con la citada carta de 1554 , la hipótesis no llegó a ser aceptada. Cf. D’Intino (1989).

9. Catz (1978), Collis (1949). 
certeza, entre otras cosas, porque el manuscrito desapareció y su editor, el cronista Francisco de Andrade, murió poco tiempo después de la aparición de la edición príncipe.

A pesar de ello, el conocimiento de Pinto sobre asuntos relacionados con Oriente fue muy valorado y reconocido ya en vida del autor. Sabemos que en 1582 Giovanni Pietro Maffei lo entrevistó en busca de datos útiles para escribir su historia sobre la misión de los jesuitas en Japón. ${ }^{10}$ Sin duda, uno de los intereses principales en la información que poseía Pinto tiene que ver con la labor del padre Francisco Javier en Oriente, que ocupa nada menos que veintiséis capítulos de su obra (CC-CCXXVI). Al parecer el manuscrito pudo ser consultado mientras esperaba su llegada a la prensa en la Casa Pia das Penintentes, adonde lo llevaron los hijos del escritor después de su muerte. Allí fue utilizado por varios miembros de la Compañía, que buscaban datos para escribir sus obras, entre los que se cuentan con mayor certeza: Horacio Torsellini para su De vita Francisci Xavierii Libri Sex (1594), João de Lucena para la História da vida do Padre Francisco Xavier (1600) y Fernão Guerreiro para su Relaçam Anual(1602-1612). Giovanni Botero lo menciona en las Relationi Universali publicadas en Roma en 1591-1592. ${ }^{11}$ Roque de Oliveira añade a esta lista al carmelita Jerónimo Gracián de la Madre de Dios como el primer autor que en 1586 utilizó fragmentos de la Peregrinaçam en el Stimulo dela propagación dela Fee. ${ }^{12}$

Si pensamos en la cantidad de manos por las que pasó el texto manuscrito antes de darse a la imprenta, es fácil entender todas las hipótesis que se han barajado acerca de la intervención de otro(s) agente(s) que habrían añadido algo más que la simple dedicatoria a Felipe III. ${ }^{13}$ Lo único que podemos dar por cierto es que el cronista Francisco de Andrade se encargó de editar la obra, que obtuvo el privilegio real en 1613, aunque las licencias fueron concedidas en 1603, y que salió a la luz al año siguiente. No es mi propósito, en este lugar, el de adentrarme en la compleja cuestión de las muchas interpretaciones posibles del texto, que ha sido leído como sátira, sátira picaresca, narración utópica y antecedente del iluminismo, o en las intenciones que le han querido atribuir al escritor, quien por su parte se limitó a manifestar el único deseo de dejarlo como herencia a sus hijos. Sí interesa, en cambio, recordar que el autor de la Peregrinaçam se ganó en poco tiempo fama de embustero, y que la veracidad de su relato fue puesta muy pronto en tela de juicio, no solamente por las incongruencias en los datos que proporciona en la narración o por la evidente ficcionalización de algunos episodios sino, sobre todo, porque el autor

10. La entrevista fue descubierta por el padre Georg Schurhammer en 1924. (Cf. Catz, 1989).

11. Catz (1978).

12. Oliveira (2003: 900-909).

13. Incluso se ha dicho que la obra fue redac- tada como una extensa carta autobiográfica. Cf. Casais Monteiro (1972). Por su parte, Roque de Oliveira (V. Supra n.7 ) defiende la idea de la implicación de los jesuitas en las posibles modificaciones. 
se proclama descubridor de Japón en el capítulo CXXXVIII. ${ }^{14}$ De ahí el juego de palabras, que ya se hizo costumbre referir al hablar del portugués: Fernão, mentes? Minto. ${ }^{15}$

Sea como fuere, no ha de descartarse que la tardanza de la publicación pudiera responder tanto al mal estado del manuscrito o a las supuestas falsedades del autor como al deseo de controlar la circulación de las noticias sobre oriente. Con la impresión de la traducción castellana de Herrera Maldonado se inicia, por así decir, la segunda parte de la historia de la obra y se abren las puertas para la difusión del relato de Mendes Pinto en toda Europa.

La versión española de la Peregrinaçam, que publicó Francisco de Herrera Maldonado, es decir, la Historia oriental de las peregrinaciones de Fernán Méndez Pinto, venía acompañada de una «Apología en favor de Fernán Méndez Pinto y desta historia oriental» que concluía con el «Catálogo». ${ }^{16}$ El propósito de estos preliminares era la defensa de la veracidad del texto y de la credibilidad de su autor, a quien Herrera profesaba una gran admiración a pesar de que, como hemos dicho, se había ganado ya fama de farsante. La otra finalidad podría haber sido realizar una especie de justificación de su trabajo que consistió en un traslado bastante libre del texto portugués. ${ }^{17}$ Según él mismo apunta, la escasa calidad de la edición portuguesa impide la traducción palabra por palabra, aunque, afirma:

14. Cortesão (1975) defiende y explica los detalles del malestar causado entre algunos por esta afirmación. Por otra parte se conocen estudios de la primera mitad del xx que confirman algunas de las referencias a nombres propios dadas en la Peregrinaçam en Okamoto (1929). 15. Se puede establecer un paralelismo entre la fama de mentiroso de Mendes Pinto y la del autor del otro gran relato de aventuras de época anterior a la Peregrinaçam, me refiero al libro de Marco Polo que se conoció popularmente como Il Milione, al parecer por su carácter poco ajustado con la realidad de la época y las exageraciones que contenía su narración. Como en el caso del portugués, también algunos de los datos proporcionados por el veneciano se han confirmado en los últimos siglos.

16. Francisco de Herrera Maldonado nació en Oropesa fue licenciado en teología y canónigo de la iglesia de Arbas de León. Figura en el Catálogo de Autoridades de la Lengua Españolay, según se dice, fue gran amigo de Lope de Vega - quien le dedica la silva segunda en el Laurel de Apolo. Escribió también un Discurso panegírico y descendencia de los Toledos de Castilla (1622); una Relación de los casamientos del sexto conde de Oropesa don Fernando Alvarez de
Toledo, que se cita en el discurso panegírico y el Libro de la vida y maravillosas virtudes del Siervo de Dios Bernardino de Obregón, padre y fundador de la Congregación de los enfermeros pobres, $y$ autor de muchas obras pías en Madrid y otras partes (1633); realizó también otros trabajos de traducción entre los que se pueden localizar un Sannazaro español. Los tres libros del parto de la virgen Nuestra Señora (1616) y un Luciano español: diálogos morales, útiles por sus documentos (1621). En la Enciclopedia universal ilustrada Europeo Americana: apéndice 1934-2002, Madrid: Espasa-Calpe, DL 2002.

17. Menéndez Pelayo desestimó la fidelidad de las traducciones de Herrera al comentar su versión de Luciano en la que «tradujo del latín con tan escaso respeto al texto que interpretaba, que no dudo en añadir pensamientos, frases, períodos y hasta páginas enteras (...) Aun en los pasajes menos corrompidos por el mal gusto, cuesta trabajo reconocer a Luciano envuelto en las innumerables perífrasis, circunloquios y amplificaciones retóricas de su sacrílego intérprete». Afirma que más que una «bella infiel» la versión del Luciano de Maldonado es una «fea infidelísima». En Biblioteca virtual Menéndez Pelayo. 
lo hicimos sin apartarnos del sentido cierto de los asuntos, poniendo todo cuidado en buscar frases propias, y eligiendo palabras que tuviesen mayor parentesco y energía con las estrañas, sin faltar al tiempo suceso, modo y caso (...)

El resultado es un texto bastante más extenso que el original «siendo forzoso vestir de contentos y sentencias esta escritura de que estaba mendicante».

Herrera ejerció una labor similar a la de un corrector de estilo, modificó la estructura de los párrafos y cambió expresiones del autor para dar al texto un carácter más elaborado que, de alguna manera, permite una lectura más fluida. En ocasiones, introduce sentencias moralizantes o datos históricos y, cuando se percata, corrige errores presentes en el original. En la mayoría de los casos cambia la primera persona, que el narrador/autor (o alguien por él) usa para titular los capítulos, por la tercera persona del autor, aunque la mantiene en el contenido, y resta así importancia al sentido de relato autobiográfico. ${ }^{18}$ Esta variación es consecuente con la primera diferencia que se percibe a simple vista entre la versión portuguesa y la española: el cambio de título de Peregrinaçam a Historia oriental. Es decir, el paso de un relato testimonial de carácter individual, si se quiere autobiográfico, la historia de un personaje particular, a Historia oriental y sólo en segundo lugar, el relato de las peregrinaciones de Fernán Méndez Pinto. En un momento en el que ya se han escrito las principales historias de las Indias occidentales, poner la obra del portugués, al menos en el título, en el mismo nivel de la Historia general y natural de las Indias de Gonzalo Fernández de Oviedo (1535-1557) o de la Historia general de las Indias y conquista de Nuevo México de Francisco López de Gómara (1552) significaba dotarla del prestigio y del carácter de veracidad que, a su vez, constituía parte de la defensa del traductor frente a quienes calificaban a Pinto de mendaz. ${ }^{19}$

En la Apología, Herrera recurre a dos argumentos centrales para exculpar de las acusaciones al autor y a su obra. Critica al editor portugués Francisco de Andrade quien «dejó tan imperfeto este libro que antes que corregirle le ofendió de nuevo" y motivó la desconfianza en "hombres de talentos apestados». Lo acusa hasta de los descuidos estilísticos de Mendes Pinto, porque este, al cabo, nunca habría pretendido que a su libro «le viesen tantos ojos», mientras que el editor, que debía remediar tales fallos antes de sacar la obra a la luz, se conformó

18. A modo de ejemplo, en los primeros capítulos del texto portugués de 1614: «Do que passey em minha mocidade neste Reyno até que me embarquei para à India»/ "Como deste Reyno me partí para à India $\&$ do successo que teve a armada em que fuy»/ «Como de Diu me embarquey para o estreito de Meca, \& do que passei nesta viagem». En la versión española de 1620: «Cuenta el autor su nacimiento, mocedad y sucesos en el reino de Portugal hasta embarcarse para la India»/ «Parte el autor del reino de Portugal para la India, suceso que tuvo la armada en que fue»/ «Sucesos del autor, desde la fortaleza de Diu hasta que llegó al estrecho de Meca».

19. Oliveira (2003: 1329) menciona como contrapunto de la Historia oriental la Historia general de las Indias de Bartolomé de las Casas, aunque esta se publicó en 1875 , por tanto no se puede asegurar que Herrera tuviera conocimiento de su existencia. 
tan sólo con dividirla en capítulos. Aunque cabe notar que el mismo Herrera mantuvo dicha división, pese a tener acceso al original según nos dice en el mismo texto.

La segunda estrategia de defensa se funda en los argumentos de autoridad. Herrera cita a lo largo de las páginas que ocupan la Apología a numerosos autores que han escrito sobre oriente, bien para demostrar la coincidencia de información con el texto de Pinto, bien para criticar los errores cometidos por algunos escritores cuyo testimonio es fruto de la erudición libresca en clara desventaja frente al autor portugués, que se había basado en su experiencia personal. No cuenta lo que ha leído sobre oriente sino que posee conocimiento directo y, en la mayoría de los casos, es testigo presencial o protagonista de los hechos que narra. La autoridad concedida a la obra radica no tanto en el testimonio recogido por otros autores como en la experiencia del escritor. ${ }^{20}$ Sin embargo, aunque esgrime el argumento del conocimiento directo, a los mismos autores que critica por no ser testigos los usa, cuando es conveniente, como fuentes para confirmar otros apartados de la Peregrinaçam. Es el caso de Juan González de Mendoza, viajero de sillón que escribió la Historia del gran reino de la China, citado en más de una ocasión en la Apología para avalar la información que da Pinto sobre territorio sínico, para el "gobierno de aquellos reinos, de la rectitud de la justicia, nombre de jueces, virreyes, magistrados, capitanes, gobernadores y ministros de sus hábitos, insignias, particularidades y costumbres» o para la tan citada referencia a su particular método para criar ánades. Más adelante, desautoriza la afirmación de Mendoza sobre la ausencia de castillos y fortalezas, y alude a la necesidad de:

averiguar el engaño deste padre con autores auténticos y que muchos años cursaron aquellas tierras y no quisieron fiar su opinión de relaciones mal entendidas, porque así quede más sabida la verdad de Fernán Méndez

Por otro lado, recurre, por ejemplo, a un autor como João de Lucena en su História da vida do Padre Francisco Xavier quien, como hemos señalado, en su momento extrajo información del texto de Pinto. Casos como este se repiten a lo largo de la lista del Catálogo que comentaremos líneas abajo.

Tal vez la Apología de Herrera estuvo más motivada por la admiración que sentía por el portugués, "hombre de agudo ingenio, de singular memoria y de experiencias notables», que por la posibilidad de corroborar la información que contenía su colosal obra. Lo único cierto es que gracias a la polémica iniciada

20. Tal y como Bernal Díaz del Castillo usó la preeminencia de lo visto sobre lo vivido para autorizar su Historia verdadera de la conquista de la Nueva España en oposición a historiadores que nunca pisaron el Nuevo Mundo como López de Gómara. La obra de Castillo llegó a
España en 1575 pero se publicó en 1632. Es probable que, como en el caso de la Peregrinaçam, circulara de forma manuscrita antes de imprimirse. Bernal Díaz elabora su relato en base a su propia experiencia, prescinde de la erudición y se opone a la historiografía de oídas. 
en Portugal, que Herrera reaviva con la traducción y responde en la Apología, la Peregrinaçam se salvó del olvido al que habría estado condenada. Así lo demuestran las ediciones de la Historia oriental que se publicaron en Espańa: dos en 1620, una en 1627-1628, 1645, 1664 y 1666, mucho antes de la segunda y última portuguesa del siglo en 1678.Las traducciones en otras lenguas europeas se sucedieron rápidamente: la primera es la francesa de 1628, que se basaba en la castellana e incluía la Apología de Herrera Maldonado. Le siguieron la holandesa de 1652 y la inglesa de 1653, en la que se publicaron 81 capítulos y se omitió todo lo relativo a la vida de Francisco Javier, aunque se volvió a incluir el texto del traductor español. Finalmente, la alemana se publicó en Amsterdam en $1671 .{ }^{21}$ Méndez Pinto se convirtió en el peregrino más célebre de la literatura del XviI, su historia llegó a un público bastante diverso como lo demuestra la versión teatral que se escribió antes de 1663: Fernán Méndez Pinto, Comedia famosa en dos partes. ${ }^{22}$

\section{El Catálogo}

Herrera Maldonado completa las estrategias de autoridad mencionadas en la Apología con el Catálogo porque las noticias que presenta el autor, por ser muy novedosas, pueden ser tomadas por falsas por hombres indoctos. Dice el traductor:

me pareció necesario averiguar estas verdades con autores auténticos y científicos, probando las cosas más admirables destos discursos, y que a la primera vista los entendimientos que la tienen tan corta, les parecen imaginaciones o milagros, remitiendo en lo demás al curioso, a los autores de aquel Oriente, de que le haré un catálogo por si quisiere, como yo ahora, lo mayor y famoso, averiguar lo que fuere menos.

Si el catálogo cumple o no este objetivo es una cuestión que no nos cabe considerar aquí. Lo importante es que Herrera con su listado nos dejó un documento capital que permite localizar algunas de las lecturas a las que el público letrado tenía acceso para informarse sobre los codiciados territorios orientales, principalmente, el reino de la China. Las obras que menciona componen la «biblioteca oriental» de comienzos del siglo xviı y la interpretación de su contenido es imprescindible para comprender cómo se inicia la construcción de ese oriente libresco, que es, en definitiva, el reflejo de la empresa imperial de Europa, que intenta definir los nuevos territorios desde el punto de vista occidental. La procedencia ideológica y geográfica de las obras nos confirma, una vez más, que el Imperio se ha servido siempre de la actividad intelectual para sus propósitos económicos y políticos y que los conflictos de poder sobre el terreno, en este caso religioso, se podían librar con ayuda de la pluma.

21. Vid. infra las referencias completas de estas ediciones.

22. Cohen (1974). 
Considerando su importancia, presentamos el catálogo con el fin de posibilitar la identificación de las referencias, a menudo muy sumarias, y, por tanto, incompletas. En ocasiones, la referencia es demasiado vaga o los nombres, en su mayoría portugueses, aparecen adaptados al castellano, lo que dificulta la identificación de algunos textos. En algunos casos, muy pocos, no he conseguido identificar de forma inequívoca la obra citada. Transcribo a continuación el catálogo, siguiendo la princeps y numerando las entradas, y, seguidamente, dispongo la relación de obras citadas con referencia completa a la primera edición encontrada.

\section{Catálogo de los autores que han escrito de las Indias Orientales, Japón y China y de sus situaciones, navegación y conquistas}

(1) Juan de Barrios, Tres décadas, Historia general

(2) Fernán López de Castañeda, Historia general

(3) Don Jerónimo Osorio, obispo de Algarve, Historia del rey don Manuel

(4) Damián de Gois, Crónica del mismo rey don Manuel

(5) Antonio Galván, Historia general

(6) Antonio Galván, Sus descubrimientos

(7) Juan Pedro Mafeo de la Compañía de Jesús, Historia general

Sus cartas del Japón y China

(8) Las cartas del Japón y China del padre Guerrero

(9) Las cartas del padre Luis Froys

(10) El libro de las cartas de los padres de la Compañía de Jesús

(11) El padre Juan de Lucena de la Compañía, vida del padre Francisco Xavier

(12) La misma vida por Ribadeneira

(13) La historia general del padre Luis de Guzmán

Sus misiones orientales

(14) La historia oriental del padre Ribadeneira

(15) El padre Antonio Pineiro, Sucesos del Japón

(16) García de Resende, Crónica del rey don Juan el segundo de Portugal

(17) Francisco de Andrada, Crónica del rey don Juan el tercero de Portugal

(18) Marco Paulo Veneto

(19) Fray Antonio de Sanrromán, Placentino, Historia general muy curiosa

(20) Las lusiadas de Camois

(21) Fray Juan González de Mendoza, Historia de la China

(22) La misma de Fray Gaspar de la Cruz

(23) El patriarca don Juan Bermúdez, Historia de Etiopia

(24) La misma de Pedro de Mezquita

(25) Francisco Álvarez, Historia del preste Juan

(26) Fray Gaspar Dominico, Su itinerario

(27) Diego de Couto, Su cuarta década 
(28) Homeron, Historia

(29) Juan Bohemio de moribus gentium

(30) Gabriel Revelo, relación de las islas Malucas

(31) San Anselmo, de imagine mundi

(32) Fray Juan de Pineda, Su monarquía

(33) Los comentarios de Alfonso de Alburquerque

(34) El itinerario de Juan Pérez

(35) Serafino Rozi, Crónica de Santo Domingo

(36) La misma de fray Hernando del Castillo

(37) Fray Diego Deza, cuarta parte de las crónicas de San Francisco

(38) Luis de Páramo, de origine inquisitionis

(39) Jerónimo Querubín, relaciones de Etiopía

(40) Juan de Botero en sus relaciones

(41) Jaime Rebullosa, su historia Eclesiástica

(42) Luis de Bavia, la tercera parte de la pontifical

(43) Pedro Teixeira, relaciones de Persia y Ormuz

(42) Mircond en su Tarique

(45) Fray Antonio de Govea, relaciones de Persia

(46) Duarte Fernández, relaciones de Pegu

(47) D. Diego de Herrera, las islas Malucas

(48) El itinerario de Mendoza

(49) El Barrachel Enciso, de la isla de Santiago

(50) El itinerario de Guerrero

(51) Los comentarios de Mateo Ricio

(52) Las cartas de Valignano

(53) Casas, obispo de Chiapa

(54) Lope de Sosa Coutiño, el primero cerco de Diu

(55) El mismo Francisco de Andrade

(56) El segundo Jerónimo Corte Real

(57) El mismo de Diego de Teve

(58) Jorge de Lemos, Cerco de Malaca

(59) Antonio del Castillo, Comentarios del cerco de Goa

(60) Comentarios del virrey don Juan de Castro

(61) Antonio Pinto, de las cosas del virrey don Luis de Ataide

(62) Pedro de Mariz, Historia

(63) Bernardino Escalante

(64) Viaje de Ludovico Patricio

(65) Jerónimo Corte Real, Naufragio de Manuel de Sosa

(66) Manuel Godinio, Naugrafio de la nao Santiago

(67) Manuel de Mezquita, de la nao de San Benito

(68) Juan Bautista Lebaña, naufragio de la nao san Alberto

(69) Tres naufragios de las naos San Juan, Santa María de la Barca de San Pablo y Santo Tomás 
(70) Sucesos del galeón Santiago, por Melchor Estacio de Amaral

(71) Nicolau Trigaucio, expeditione Christiana apud Sinas

\section{El Catálogo actualizado}

(1) João de Barros, Asia de Joam de Barros dos fectos que os portugueses fizeram no descobrimento \& conquista dos mares \& terras do Oriente. Primeira decada. - En Lisboa: per Germão Galharde, 28 Junho 1552. Segunda decada. — En Lisboa: per Germão Galharde, 24 Março 1553. Terceira decada. — En Lisboa: por Ioam de Barreira, 1563.

(2) Fernão Lopes de Castanheda, História do descobrimento \& conquista da India pelos portugueses / por Fernáo Lopes de Castanheda; Barreira, João de, fl. 1542-1590, impr.; Álvares, João, fl. 1536-1587?, impr. [Volumen I - 1551 (2a edición en 1554), volúmenes II e III - 1552, volúmenes IV e V - 1553, volumen VI — 1554 e volumen VIII — 1561. O volumen VII publicado sin fecha ni lugar]

(3) Auctore Hieronymo Osorio episcopo Sylvensi.De rebus Emmanuelis regis Lusitanice invictissimi virtute et auspicio gestis libri duodecim [Texte imprimé]. Olysippone. Apud Antonium Gondisalvum typographum. Anno Domini. M. D. LXXI. Cum privilegio regio.

(4) Damião de Góis, Chronica do Felicissimo Rei Dom Emanuel composta per Damiam de Goes diuidida em quatro partes...; En Lisboa: em casa de Francisco Correa, 1566-1567.

(5) Texto perdido de Antonio Galvão História das Molucas, da naturaza e descubrimento daquellas terras, dividida em 10 livros (B.L)

(6) Antonio Galvão, Tratado que compôs o nobre \& notauel capitão Antonio Galuão, dos diuersos \& desuayrados caminhos, por onde nos tempos passados a pimenta \& especearia veyo da India às nossas partes, \& assi de todos os descobrimentos antigos \& modernos, que são feitos até a era de mil \& quinhentos \& cincoenta...; [Lisboa]: impressa em casa de Ioam da Barreira, impressor del rey nosso senhor, na Rua de sã Mamede, 15 Dezembro 1563.

(7) Ioannis Petri Maffei...Historiarum Indicarum libri 16. Selectarum item ex India epistolarum eodem interprete Libri 4. Accessit Ignatii Loiolae vita postremo recognita. Et in opera singula copiosus Index; Firenze, I. Giunta[editore], 1589.

(8) Guerreiro, Fernão (S. J., Le P.), Relaçam annual das cousas que fizeram os Padres da Companhia de Jesus na India e Japão, nos annos de 600 e 601... pello padre Fernão Guerreiro,... Evora: por M. de Lyra, 1602.

Relaçam annal [sic] das cousas que fezeram os padres da Companbia de Jesus mas partes da India oriental, \& no Brasil, Angola, Cabo Verde, Guine, nos annos de seiscientos \& dous \& seiscientos \& tres, \& do processo da conversam, \& christiandade daquellas partes, tirada das cartas dos mesmos padres que de lá vieram. Pelo padre Fernam Guerreiro... vay dividido em quatro livros...En Lisboa : per Jorge Rodrigues, 1605 . 
Relaçam annal [sic] das cousas que fezeram os padres da Companhia de Jesus mas partes da India oriental, \& em alguas outras da conquista deste reyno nos annos de 604. \& 605. \& do processo da conversame christiandade daquellas partes, tirada das cartas dos mesmos padres que de lá vieram. Pelo padre Fernam Guerreiro... vay dividido em quatro livros...En Lisboa: por Pedro Crasbeeck, 1607. Relaçam annal [sic] das cousas que fezeram os padres da Companhia de Jesus mas partes da India oriental, \& em alguas outras da conquista deste reyno nos annos deDESTE REYNO NOS 606. \& 607. \& do processo da conversame christiandade daquellas partes, tirada das cartas dos mesmos padres que de lá vieram. Pelo padre Fernam Guerreiro... vay dividido em quatro livros... o primeiro da prouincia do Iapão, \& China. O segundo da prouincia do sul. O terceiro da prouincia do norte. O quarto de Guiné, \& Brasil... En Lisboa : por Pedro Crasbeeck, 1609. Relaçam annal [sic] das cousas que fezeram os padres da Companhia de Jesus mas partes da India oriental, \& em alguas outras da conquista deste reyno nos annos deDESTE REYNO NOS 607. \& 608. \& do processo da conversame christiandade daquellas partes, com mais hua addiçam à relaçam de Ethiopia... En Lisboa: impresso por Pedro Crasbeeck, 1611.

(9) Fróis, Luís (1532-1597), Lettera annale del Giapone scritta al Padre generale della Compagnia di Giesù alli 20. di febraio 1588; Roma: F. Zannetti, 1590.

(10) Alguns capitulos tirados das cartas que vieron este anno de 1588 dos Padres da Companhia de Iesu que andam nas partes da India, China, Iapão, \& Reino de Angola... / Collegidos por o Padre Amador Rebello ....En Lisboa : per Antonio Ribeyro, 1588

Cartas que os padres e irmãos da Companhia de lesus escreuerão dos Reynos de Iapão \& China aos da mesma Companhia da India \& Europa, des do anno de 1549 até o de 1580.En Euora : por Manoel de Lyra, 1598.

Copia de algunas cartas que los padres y hermanos de la compañia de Iesus que andan en la India y otras partes orientales escriuieron a los de la misma compañia de Portugal, desde el año de M.D.LVII. hasta el de lxj. I tresladadas de portugues en castellano. Impressas en Coimbra: por Ioan de Barrera, 1562 (por Iuan Aluarez)

(11) Lucena, João de, 1550-1600, S.J, Historia da vida do padre Francisco de Xavier : e do que fizerão na India os mais religiosos da Companhia de Iesu / composta pelo padre Ioam de Lucena, da mesma Companhia, portugues, natural da Villa de Trancoso. En Lisboa: por Pedro Crasbeek, 1600.

(12) Ribadeneyra, Pedro de, 1527-1611, Vida del P. Francisco de Borja, que fue duque de Ga[n]dia, y después religioso y.III. general de la Compañia de Iesús I Escrita por el P. Pedro de Ribadenayra de la misma Compañia. Madrid : en casa de P. Madrigal, 1592.

(13) Luis de Guzmán, Historia de las Missiones que han hecho los Religiosos de la Compañia de Iesvs, para predicar el Sancto euangelio en la India Oriental, y en los Reynos de la China y Iapon [Texto impreso] : Primera [segunda] Parte. Publicación: Alcala : por la Biuda de Iuan Gracian, 1601-2. 
Historia de las Missiones que han hecho los Religiosos de la Compañia de Iesvs, para predicar el Sancto Euangelio en los Reynos de Iapon... [Texto impreso] : Segunda parte en la qual se contienen siete libros con los quales se remata la Historia de los Reynos de Iapon, hasta el Año de mil y seyscientos...Alcala : Por la Biuda de Iuan Gracian, 1601.

(14) Ribadeneyra, fr. Marcelo de, Historia de las Islas del Archipiélago y reinos de la Gran China, Tartaria Cuchinchina, Maláca, Siam, Camboxa y Jappon y de lo sucedido en ellos a los religiosos descalzos de la orden del seraphico Padre S. Francisco de la Provincia de San Gregorio de las Philipinas, Barcelona : Emprenta de Gabriel Graells y Giraldo Dotil, 1601.

(15) Piñeiro, Luis, 1560-1620, Relacion del sucesso que tuuo nuestra Santa Fe en los reynos del Iapon, desde el año de seyscientos y doze hasta el de seyscientos y quinze, imperando Cubosama...[Texto impreso], En Madrid : por la viuda de Alonso Martin de Balboa, 1617.

(16) Resende, Garcia de, Livro das obras de Garcia de Resende que tracta da vida e grandissimas virtudes e bondades... do christianissimo... principe el rey dom Joam ho segundo... e dos reys de Portugal ho trezeno... [Texto impreso], Evora: A. de Burgos, 1554

(17) Andrade, Francisco de, 1540-1614; Cronica do muyto alto e muito poderoso Rey destes reynos de Portugal Dom João o III. deste nome... / composta por Francisco d'Andrada. Impresa em Lisboa: Jorge Rodriguez : ha custa do autor : vendesse na Rua Nova em casa de Francisco Lopez livreiro, 1613.

(18) Marco Paulo Veneto, El libro del famoso Marco Paulo veneciano de las cosas marauillosas que vido en las partes orientales: conuiene saber en las Indias, Armenia, Arabia, Persia \& Tartaria. E del poderio del gran Can y otros reyes. Con otro tratado de micer Pogio Florentino que trata de las mesmas tierras \& islas, Sevilla: Lançalao Polono y Jacome Cromberger, 1503.

(19) San Román, Antonio de (O.S.B.): Historia General de la Yndia Oriental [Texto impreso]: los descubrimientos y conquistas que han hecho las armas de Portugal en el Brasil yen [sic] otras partes de Africa y de la Asia y de la dilatacion del Santo Evangelio por aquellas grandes Provincias desde sus principios hasta el años de 1557 / compuesta por Fray Antonio de San Roman monge deSan [sic] Benito ...En Valladolid : por Luis Sanchez : acosta de Diego Perez ..., 1603.

(20) Camóes, Luís de, 1524?-1580; Os Lusiadas; Lisboa : em casa de Antonio Gôçaluez, 1572.

(21) González de Mendoza, Juan (OSA), 1545-1618; Historia de las cosas mas notables, ritos y costumbres del gran Reyno de la China, sabidas assi por los libros de los mesmos chinas [sic], como por relacion de religiosos y otras personas que han estado en el dicho Reyno / hecha y ordenada por ... Iuan Gonçalez de Mendoça ... y nueuamente añadida por el mesmo autor ...; con vn itinerario del Nueuo Mundo; Impressa en Madrid : en casa de Querino Gerardo ... : a costa de Blas de Robles, 1586.

(22) Cruz, Gaspar da, ?-1570, O.P.; Tractado em que se côtam muito por este[n]so as 
cousas da China cô suas particularidades e assi do reyno dormuz [sic] / cóposto por el R. padre fray Gaspar da Cruz da orde[m] de sam Domingos... Euora : em casa de Andre de Burgos, 1569.

(23) Bermudes, João, ?-1570; Esta he hu[m]a breue relação da embaixada q[ue] o patriarcha dó Ioão Bermudez trouxe do Emperador da Ethiopia chamado vulgarmente Preste Ioão ao christianissimo zelador da fee de Christo Rey de Portugal dom Ioão o terceiro deste nome... Em Lixboa : em casa de Francisco Correa, 1565.

(24) La misma de Pedro de Mezquita. (No encontrado) En B.L aparece Pedro de Mesquita autor de una História da Etiopia, ninguna referencia al año. «Assitio muitos annos no império da Etiopia, onde examinando com juizo de sabio e investigaçáo de curioso os costumes e ritos de seus habitadores como as plantas e arvores que prduz o seu terreno escreveo.....» (Tomo III, p. 601)

(25) Álvares, Francisco, 1470-1540; Ho Preste Ioam das Indias : verdadera informaçam das terras do Preste Ioam / segundo vio \& escreueo ho padre Francisco Aluarez, capellã del rey nosso señor; [Lisboa] : em casa de Luis Rodriguez, 22 Outubro 1540.

(26) São Bernardino, Gaspar de, 15 -16, O.F.M; Itinerario da India por terra ate este Reino de Portugal com a discripcam de Hierusalem... / Composto por Frei Gaspar de Saô Bernardino.. En Lisboa : na officina de Vicente Alvares, 1611. Esta referencia es incierta puesto que su autor era franciscano y Herrera cita a un Gaspar dominico. Gaspar da Cruz pertenecía a la Orden de Santo Domingo pero no figura ningún itinerario de su autoría.

(27) Couto, Diogo do, 1542-1616; Decada quarta da Asia, dos feitos que os portugueses fizeram na conquista e descobrimento das terras, \& mares do Oriente: em quanto governaraó a India Lopo Vaz de Sam Payo, \& parte do tempo de Nuno da Cunha. Composta por mandado do muito catholico e invencivel Monarcha de Espanha Dom Filipe Rey de Portugal o primeiro deste nome / Por Diogo do Couto chronista e guarda mòr da torre do tombo do estado da India; En Lisboa: impresso por Pedro Crasbeeck, no Collegio de Santo Agostinho, 1602.

(28) Homeron, Historia

(29) Boehme, Johann, Omnium gentium mores leges et ritus ex multis clarissimis rerum scriptoribus, a Ioanne Boemo Aubano sacerdote Teutonicae militiae deuoto nuper collectos, \& in libros tris distinctos Aphricam, Asiam, Europam, optime lector lege...Augustae Vindelicorum :excusa in officina Sigismundi Grim[m] medici, ac Marci Vuirsung, 1520, mense Iulio.

(30) Rebelo, Gabriel, fl. ca 1566, ant. bibliog.; Galvão, António, 1490-1557, ant. bibliog.; Historia das Ilhas de Maluco escripta no anno de 1561 dirigida a D. Constantino vicerey, que foy da Índia dividida em três partes. A 1 trata em 13 capitulos as cousas notáveis que há no Maluco, e dos costumes dos moradores delle. A 2 trata em 12 capitulos do seu descobrimento assim pelos portugueses, como pelos castelhanos com todas suas armadas até a de que foy Geral Ruy Lopes de Villalobos. A 3 trata em 13 capitulos das cousas que sucederão em tempo do capitão Bernardim de Souza até destruir as fortalezas de Geilolo e Tidore [ Manuscrito / [Gabriel 
Rebelo] (Trata-se provavelmente de uma adaptação da obra «Informação das Cousas de Maluco", de Gabriel Rebelo.) PUBLICAÇÃO:[17--] (BNP)

(31) Honorius Augustodunensis; De imagine mundi [Texto impreso]; Fecha de pub: c.1472]. Referencia más próxima.

(32) Pineda, Juan de, 1558-1637; Los Treynta libros de la Monarchia ecclesiastica, o Historia universal del mundo, divididos en cinco tomos... / compuestos por fray Juan de Pineda ... En Salamanca : en casa de Juan Fernandez: a costa de Hylario de Bonefont ..., 1588.

(33) Albuquerque, Afonso de, 1462-1515; Albuquerque, Afonso de, 1500-1580; Commentarios de Afonso Dalboquerque capitão geral e gouernador da India, collegidos por seu filho Afonso Dalboquerque das proprias cartas que elle escrenia ao muyto poderoso Rey dó Manuel o primeyro deste nome, em cujo tempo gouernou a India...Lisboa: por Ioam de Barreyra, 19 Ianeyro 1557.

(34) El itinerario de Juan Pérez

(35) Razzi, Serafino O.P, Vita degli huomini, come donne del sacro ordine defrati predicatore, in Firenze, apresso Bartolomeo Samartelli, 1577.

(36) Castillo, Hernando del (O.P.), 1529-1595; Primera-segunda parte de la Historia general de Santo Domingo y de sv orden de predicadores / por el maestro fray Hernando de Castillo; Impressa en Valencia: en casa de Pedro Patricio Mey .... a costa de Balthasar Simon ..., vendese en su casa ..., 1587-1592.

(37) Daza, Antonio (OFM); Qvarta parte de la Chronica General de Nu[es]tro Padre San Francisco y su apostolica Orden compuesta por Fray Antonio Daça.Impresa en San Francisco de Valladolid : por Juan Godines de Millis y Diego de Cordoua, 1611.

(38) Páramo, Luis de, n. 1545; De origine et progressu Officii Sanctae Inquisitionis eiusque dignitate \& utilitate, de romani pontificis potestate \& delegata Inquisitorum, edicto fidei \& ordine iudiciario Sancti Officii quaestiones decem, libri tres I autore Ludovico à Paramo ... Madriti : ex Typographia Regia, 1598 (Matriti : apud Ioannem Flandrum)

(39) Jerónimo Querubín, relaciones de Etiopía

(40) Botèro, Giovanni ca. 1543-1617; Delle relationi vniuersali di Giouanni Botero... parte prima [-seconda]. - In Roma : nelle case del Popolo Romano, appresso Giorgio Ferrari (to.1:nella stamperia di Bartolomeo Bonfadino), 1592 - 1597. - 2 to. in 1 v. ([8], 403, [12] p.; [4], 289, [14] p.); 4. ((to.2:Ad istanza di Giorgio Ferrari, 1592 (nelle case del Popolo Romano, appresso Giorgio Ferrari, 1597). — to. 1: 1595.

Botèro, Giovanni (ca. 1543-1617); Relaciones uniuersales del mundo [Texto impreso] I de Iuan Botero Benes; primera y segunda parte; traduzidas ... por ... Diego de Aguiar ... Impresso en Valladolid : por los herederos de Diego Fernandez de Cordoua : vendese en casa de Martin de Cordoua, 1599.

(41) Rebullosa, Jaime (ca. 1560-1621); Historia eclesiastica y estado presente de la religion en todos los reynos de Europa, Asia, y Africa [Texto impreso] / sacada de las Relaciones toscanas de Iuan Botero Benes; por Iayme Rebullosa, de la Orden de 
Predicadores; al ... señor Luis Sans ... En Barcelona : por Hieronymo Margarit : y a su costa, 1610(en Barcelona) : en la estampa de Iayme Cendrat, 1608.

(42) Bavia, Luis de (1555-1628); Tercera Parte de la Historia Pontifical y Católica [Texto impreso] / ompuesta ... por el D. Luis de Bauia ... ; dirigida a Don Christoual Gomez de Sandoual y Rojas, Duque de Cea ... ; contiene esta tercera parte ... las cosas mas notables sucedidas en el mundo, desde el año de mil y quinientos $y$ setenta y dos, hasta el de mil y quinientos y nouenta y vno; En Madrid: Por Luis Sanchez ... y a su costa, 1608.

(43) Albernaz, Pedro Teixeira, 1575-1660; Relaciones de Pedro Teixeira d'el origen descendencia y succession de los reyes de Persia, y de Harmuz y de un viage hecho por el autor desde la India Oriental hasta Italia por tierra; En Amberes: en casa de Hieronymo Verdussen, 1610.

(44) Mirkond Tarik, cronista persa (B.L)

(45) Gouveia, António de, fl. 1575-1628, O.E.S.A.;Relaçam, em que se tratam as guerras e grandes victorias que alcançou o gräde Rey da Persia Xá Abbas do grão turco Mahometto, \& seu filho Amethe as quaes resultarão das embaxadas que por mandado da Catholica Real Magestade do Rey D. Felipe II de Portugal fizerão alguns religiosos da ordem dos eremitas de Santo Agostinho à Persial composto pello Padre F. Antonio de Gouvea.. Impresso em Lisboa : por Pedro Crasbeeck: vendese na Rua Nova, em casa de Simão de Carvalho, mercador de livros, 1611 (BNP) Se tradujo al francés en 1646 según Barbosa. En 1609 había salido en Lisboa Relaçoens da Pérsia, e do Oriente, «sem nome do autor».

(46) Duarte Fernández, relaciones de Pegu

Citado en la Bibliotheca Lusitana sin más referencias a través de António de Leão e Nicol. Ant. Bib. Hisp. Relação do reino de Pegu (730)

(47) D. Diego de Herrera, las islas Malucas

Tal vez el provincial de los agustinos que perece en un naufragio en 1575 cuando navegaban de Sevilla a Filipinas (mencionado por González de Mendoza en el Libro III, Capítulo XXIV).

(48) González de Mendoza, Juan, 1545-1618, O.S.A.; Itinerario y compendio delas cosas notables que ay desde España hasta el Reyno dela China y dela China à España boluiendo por la India Oriental despues de auer dado buelta à casi todo el Mundo... / hecha por el muy reuere[n] do padre Maestro fray Iuä Gonçalez de Mendoça de la Orden de S. Augustin... Lisboa, en S. Phelippe el Real : [Andre Lobato], $1586 .^{23}$

23. Se refiere al Itinerario del padre Martín Ignacio de Loyola que aparece en la edición definitiva de la obra de Mendoza (Madrid, 1586), sólo esta parte del libro se publica en Lisboa y se omite el nombre de Loyola y se da a González como autor. En la edición princeps española figura como Itinerario del padre cus- todio fr. Martín Ignacio de la orden del bienaventurado San Francisco que pasó a la China, en compañía de otros religiosos de la mesma orden y de la provincia de Sant Joseph por orden del rey deon Phelipe nuestro señor y de la buelta que dio por la India Oriental, y otros reinos rodeando el mundo. 
(49) Fernández de Enciso, Martín; Suma de geographía que trata de todas las partidas y provincias del mundo, en especial de las Indias, y trata largamente del arte del marear, juntamente con la espera en romance, con el regimiento del sol y del norte, nuevamente hecha. [Por M. Fernández de Enciso.] — «A la fin»: Fué impressa en la nobillíssima y muy leal ciudad de Sevilla por Jacobo Cronberger Aleman, en el anno de la encarnacion de Nuestro Señor de mil y quinientos y diez y nueve [Texte imprimé]; Sevilla, 1519.

(50) Guerreiro, Francisco, 1528-?; Itinerario da viagem, que fez a Jerusalem o M.R.P. Francisco Guerreiro, Racioneiro, e Mestre da Capella da Santa Igreja de Sevilha, natural da Cidade de Beja...Lisboa Occidental : na Officina de Domingos Gonçalves, Impressor das Covas de Mont-furado, 1734.

(51) Los comentarios de Mateo Ricio que sólo se conocieron de forma manuscrita

(52) Valignani, Alessandro, Epistola P. Alexandri Valignani prouincialis de quinque e Societate Iesu pro Christi fide occisis in India Orientali anno 1583; Pubblicación: [1584].

(53) Bartolomé de las Casas (m. 1566); Las obras del obispo D. Fray Bartolome de las Casas, o Casaus, obispo que fue de la ciudad Real de Chiapa en las Indias, de la Orden de Santo Domingo... [Texto impreso]; [Barcelona] Impresso en Seuilla, en casa Sebastian de Trugillo, año 1552 y agora nueuamente en Barcelona: en casa de Antonio Lacaualleria, 1646.

(54) Coutinho, Lopo de Sousa, 1515-1577; Liuro primeyro [-segundo] do cerco de Diu que os Turcos poseram à fortaleza de Diu / per Lopo de Sousa Coutinho, fidalgo da casa do inuictissimo Rey dom Ioam de Portugal ho terceyro deste nome, Coymbra: per Ioã Aluarez, 15 Setembro 1556.

(55) Andrade, Francisco de, 1540-1614; O primeiro Cerco que os turcos puserão há fortaleza de Diu nas partes da India defendida pollos portuguesesl por Francisco Dandrada, Coimbra : [João de Barreira], 1589.

(56) Corte Real, Jerónimo, 1530-1590; Sucesso do segu[n]do cerco de Diu estando Dó Ioham Mazcarenhas [sic] por capitam da fortaleza, ano de 1546, Lisboa: per Antonio Gonçaluez, 1574.

(57) Teive, Diogo de, ca. 1514-ca. 1565; Cómentarius de rebus in India apud Dium gestis anno salutis nostrae MDXLVI / Lacobo Teuio Lusitano autore, Conimbricae : excudebant Ioannes Barrerius \& Ioannes Aluarus, 1548 (BNP)

-, Comentário da gesta portuguesa no cerco à fortaleza da cidade de Diu na Índia I Diogo de Teive; introd. e anotaçóes José Cardoso, Braga: APPACDM, 2002 (BNP)

(58) Lemos, Jorge de, ?-1593; Hystoria dos cercos que em tempo de Antonio Monis Barreto gouernador que foi dos estados da India, os Achens \& Iaos puserão à fortaleza de Malaca sendo Tristão Vaz da Veiga capitão della / breuemente composta por Iorge de Lemos...; PUBLICAÇÃO:Em Lisboa : em casa de Manoel de Lyra, 1585 (BNP)

(59) Castilho, António de, ca 1525-1593; Comentario do cerco de Goa e Chaul, no anno de MDLXX: Viso Rey Dom Luis de Ataide / scripto por Antonio de Castil- 
ho, Guarda mor da torre do Tombo, por mandado del Rey nosso Señor, Lisboa: impresso em casa de Antonio Gonsaluez, 1573 (BNP)

(60) João de Castro. Décimo quarto Governador e quarto vicerey do Estado da Índia.

Compôs Roteiro da viagem que fez deste reino para a Índia com o vicerey Garcia de Noronha no anno de 1538 e do que fez de Goa até Diu dedicado ao infante dom Luis. Estas duas obras que alguns autores intitularão Comentários geográficos os tinha prontos para a impressão Fr Fernando de Castro, religioso dominíco, neto do autor de quem se fez memória em seu lugar, e se conservão M.S na Livraria do colégio dos padres jesuitas de Évora como escrevem Maffeo ( B.L 626-631). ${ }^{24}$

(61) Pereira, António Pinto, ?-1587; Historia da India, no tempo em que a governou o Visorey Dom Luis d'Ataide / composta por Antonio Pinto Pereyra ; e agora impressa... por ordem de Frey Miguel da Cruz..., Coimbra: na impressam de Nicolao Carualho, 1616.

(62) Mariz, Pedro de, fl. 1565-1615; Dialogos de varia historia em que summariamente se referem muytas cousas antiguas de Hespanha $c$ [sic] todas as mais notauees q[ue] em Portugal acontecerlo em suas gloriosas conquistas antes e depoisde ser levantado a dignidade real, e outras muytas de outros reynos dignas de memoria: com os retratos de todos os reys de Portugall Autor Pedro de Mariz, Coimbra: na Officina de Antonio de Mariz, 1594.

(63) Escalante, Bernardino de, Discurso de la navegación que los Portugueses hacen a los Reinos y las Provincias del Oriente, y de la noticia que se tiene de las grandezas del reino de la China, Sevilla, 1577.

(64) Varthema, Ludovico de (m. 1517), Lvdovici Patritii Romani novvm itinerarivm Aethiopio: Aegipti: vtrivsque Arabia: Persidis: Siria: ac India: intra et extra Gangem [Texto impreso] / [Trad. del original italiano, por Archangelo Abadrignani]; Publicación:. [Milan] : Giovanni-Giacomo e fratello de Legnano, [S.a.], 1517 (BNE)

(65) Corte Real, Jerónimo, 1530-1590; Naufragio e lastimoso sucesso da perdiçam de Manoel de Sousa Sepúlveda \& dona Lianoe de Sá sua moler \& filos vindo da India para este Reyno na nao chamada o galião grande S. Ioão que se perdeo no cabo de Boa Esperanza na terra do Natal.../ Composto por Ieronimo Corte Real...Lisboa: na oficina de Simáo Lopez, 1594.

(66) Cardoso, Manuel Godinho, fl. 1585; Relaçam do naugrafio da nao Santiago, \& Itinerario da gente que delle se salvou. Escrita por Manoel Godinho, Lisboa[?]: impresso por Pedro Crasbeeck[?], 1602[?].

(67) Manuel de Mezquita, Naufrágio da nao Sam Beto: summario de viagé que fez Fernão d'Alvarez Cabral, aq partio pêra a Índia por capitão moor da armada aq foy ho anno de MDLIII até que se perdeo na costa do Cabo de Boa Esperança...I

24. He encontrado información de su obra en la Bibliotheca Lusitana pero ningún ejemplar en las bibliotecas consultadas 
Feyto por Manoel da Mesquita Palestrelo: [S.l. : s.n., 1996] (Fotocopia del original impreso en «Coymbra por Ioão de Barreyra, 1564» de la Biblioteca D. Manuel II existente en Vila Viçosa. - Anselmo 184)

(68) Juan Bautista Lebaña, Naufrágio da nao Santo Alberto, e itinerario da gente, que delle se salvoul por João Baptista, Lisboa[?]: en casa de Alexandre de Siqueyra[?], 1597 [?]

(69) Tres naufragios de las naos San Juan, Santa Maria de la Barca de San Pablo y Santo Tomás

Relaçaó do naufragio da nao Santa Maria da Barca... no anno de 1559.

Relaçaô da viagem, e naufragio da nao S. Paulo que foy para a India no anno de $1560 . .$. / escrita por Henrique Dias.

Relaçaó do naufragio da nao S. Thomè na Terra dos Fumos, no anno de 1589... I escrita por Diogo do Couto.

(70) Melchor Estacio de Amaral, Tratado das batalhas e sucessos do galeam Santiago com os olandezes na ilha de Santa Elena e da não Chagas com os inglezes entre as ilhas dos Açores: ambas capitanias da carreyra da Índia \& da causa \& desastres, porque em vinte annos se perderão trinta, \& oyto nãos dellal escrito por Melchor Estacio do Amaral, [Lisboa][?]: na officina de Antonio Alvares[?], 1604[?]

(71) Nicolau Trigaucio, De Christiana expeditione apud Sinas suscepta ab Societate Iesu Ex P. Matthaei Ricij Eiusdem societatis comentarijs libri V Auctore P. Nicolao Trigautio. Augustae Vindelicorum : apud Christoph Mangium, 1615.

Esta lista reúne los hitos principales del conocimiento de oriente en el occidente cristiano y, sobre todo, durante el siglo xvI. Es una excepción la referencia más antigua del Catálogo, el texto medieval que reveló a Europa por primera vez la fantástica Catay, a la que sólo regresarán más de dos siglos después los portugueses. Me refiero, lógicamente, al libro de Marco Polo (18) que, de una forma u otra, pervivió siempre como influencia indirecta en el imaginario europeo.

La naturaleza de las obras es bastante diversa. No obstante, una lectura atenta del catálogo permite entender que la característica común que hace posible comprender su sesgo ideológico y agrupar sus entradas de forma coherente, por encima incluso de la lengua y la geografía de origen, mayoritariamente portugués, es la vinculación de varios autores con órdenes religiosas. Abundan, en primer lugar, los escritores que pertenecían a la Compañía de Jesús, seguidos por dominicos y casi en igual proporción agustinos y franciscanos. Ya he tenido ocasión de mencionar aquí la importancia de la Peregrinaçam como fuente de información sobre la vida y muerte del padre Francisco Javier en oriente, tal y como reza el título. En el momento de la publicación del texto portugués, los veintiséis capítulos que el autor dedica al Apóstol de oriente son un testimonio más para la campaña a favor de su canonización, conseguida por fin en 1622. Herrera colabora, de cierta forma, con la propaganda de la Compañía al poblar el Catálogo de autores ignacianos.Destacan, en particular, las colecciones de epístolas, género convertido por los jesuitas en el medio más eficaz para difun- 
dir y promover su labor en los nuevos territorios. ${ }^{25} \mathrm{La}$ época más importante del epistolario abarca, aproximadamente, el período comprendido entre 1550 y 1570, momento en el que empieza a ser evidente la necesidad de producir documentos de carácter historiográfico, entre los que se cuentan las vidas de Francisco Javier y del mismo Ignacio de Loyola. En un principio, el epistolario se dedicó exclusivamente a los asuntos de la India, donde centraron sus primeros esfuerzos de evangelización, después a Japón y sólo a partir de 1581 a China. Sin embargo, es necesario destacar que la diferenciación temática no era exclusiva y que la información sínica se filtró desde el comienzo. Las cartas empezaron a redactarse en 1547 y a través de diferentes reformas se reguló tanto su contenido como el estilo en el que debían ser escritas pensadas siempre para una posible publicación y para lectores externos a la Compañía. Desde sus inicios se utilizaron como textos apologéticos cuyo fin era mantener la fe de los propios hermanos de la Compañía en el éxito de la misión y que aquellos que se publicaban consiguieran revelar la vocación misionera de algunos de sus lectores. En 1558 se aprobó la prescripción que el propio fray Ignacio había dejado antes de su muerte: que cada colegio enviara cartas cuatrimestrales al General residente en Roma. Pasaron a ser escritas cada seis meses en 1564 por orden de Diego Lainez, General de la Compañía desde 1558 hasta 1565, año en el que empezaron a publicarse las Littera Annuce. El destino final de las epístolas era Roma pero antes debían realizar un largo recorrido: primero hasta el seminario de las misiones en Coimbra, desde donde se enviaban copias a los colegios de Lisboa, Évora y España, y en el que podían ser sometidas a múltiples intervenciones por parte de editores, traductores y censores. Incluso, la copia de una misma carta podía variar de un lugar a otro. ${ }^{26} \mathrm{La}$ epistolografía jesuita forma un grupo de textos con un valor incalculable para la difusión de noticias sobre oriente. Pese a que el interés original radicaba en la propaganda religiosa, los misioneros recogieron datos de carácter antropológico y descriptivo que ayudaron a que el público lector buscara, además de testimonios edificantes y noticias sobre la salvación de los gentiles, detalles sobre la vida, costumbres y carácter de esos lugares exóticos y maravillosos que sólo podían imaginar a través de las descripciones de quienes estaban allí. El interés que suscitaban estas misivas puede equipararse al que tenía un relato de viajes.

Las cuatro referencias del Catálogo corresponden, en el orden que sigue, a Giovanni Pietro Maffei (7) y sus cartas del Japón y China, es decir De iaponicis rebus epistolarium libri, III, que iniciaba la correspondencia dedicada exclusivamente a tema nipón y que, en realidad, constituía un anexo del autor a la ver-

25. El tema de la epistolografía jesuita es demasiado amplio para tratarlo en estas líneas. Remito al trabajo de Roque de Oliveira (2003: 550-640) para una presentación pormenorizada de las relaciones epistolares de
China y Japón y menciono aquí tan sólo lo que considero más importante para entender su función en la difusión de noticias sobre oriente.

26. Oliveira (2003: 583). 
sión que realizó de la inédita historia del padre Manuel da Costay que lleva por título Rerum societate Iesu in Oriente gestarum ad annum usque a deipara virgine MDLXVIII commentarius Emmanuelis Acostae lusitani, recognitus, \& latinitate donatus. Accessere de iaponicis rebus epistolarium libri III item recogniti et in latinum ex hispanico sermone conuersi. Dillingen apud Sebaldum Mayer, $1571 .^{27} \mathrm{Le}$ siguen (8) las cartas del Japón y la China del padre Guerrero, que se reparten en cinco volúmenes con información un poco más tardía en 1602, 1605, 1607, 1609 y 1611 y cuya referencia aparece en el segundo catálogo páginas atrás. A continuación la obra epistolar del padre Luis de Fróis (9), quien entre 1532 y 1597 escribió un número considerable de cartas que daban noticias sobre Japón. Más imprecisa resulta la referencia al libro de las cartas de los padres de la Compañía de Jesus (10), puesto que desde el primer compendio publicado en 1551-1552 se sucede un buen número de ediciones de este tipo, sobre todo, en Portugal, España e Italia. Destacan la colección portuguesa de 1570 y las españolas de 1557, 1562 y 1575, aunque resulta imposible saber si Herrera se refería a una edición en concreto. Si se piensa que, como he dicho, las acusaciones hechas a Pinto se relacionaron sobre todo con el tema japonés, resulta probable que Herrera pensara en las cartas de Japón, que comenzó a ser tema exclusivo en la correspondencia jesuita portuguesa desde 1565. Por último, figuran las cartas de Alessandro Valignano (52) escritas desde Japón y cuya referencia no he podido localizar, salvo la de una carta publicada en $1584 .^{28}$

La otra parte de las entradas se reparte en historias o relaciones (y sus equivalentes en el caso de las demás órdenes): (7) la historia general de Pietro Maffei, que aparece junto a las cartas, publicada en 1588 y considerada una de las historias más importantes escritas por un jesuita; (11)la vida de Francisco Javier escrita por João de Lucena, la historia de Francisco de Borja, general de la orden entre 1565 y 1572, el mismo que impulsó la composición de una historia de la Compañía, y la historia general del padre Luis de Guzmán (13). No he podido localizar la relación de Japón atribuida a Antonio Pinheiro (15), aunque en la Bibliotheca lusitana III se encuentra una referecia a un Luis Pinheiro, jesuita, hijo de Antonio y autor de una relación de Japón publicada en Madrid en 1617, la coincidencia es demasiado grande para pensar que no se refiere al mismo texto. ${ }^{29}$ Son particularmente relevantes los comentarios de Matteo Ricci (51), que sólo se conocieron de forma manuscrita. Ricci fue superior de la misión de China entre 1597 y 1610 y, junto a Michele Ruggieri, uno de los agentes más importantes en el cumplimiento de la estrategia impulsada por Alesssandro Valignano para acceder al Imperio a través de la inmersión cultural, comenzó con el aprendizaje de la lengua china, y representa una forma diferente de acercarse al Otro. De los diarios del mismo Ricci se compone De Christiana expeditione 
apud Sinas...que en 1615 publica el jesuita Nicolas Trigault, última entrada del Catálogo (71).

Un año después de la aparición de la Historia oriental, Herrera publicó su Epitome historial del reino de la China (1621). ${ }^{30}$ La obra se cierra con un nuevo "Catálogo de los autores que se citan en este Epítome historial, y de donde se ha juntado lo que en él se dice». El libro se divide en veinte capítulos cuyos epígrafes refieren los temas habituales en obras de este tipo: la descripción del imperio, la fertilidad de sus tierras, la celebración de fiestas, la administración de justicia y un inesperado capítulo sobre «el milagroso aparecimiento de Cristo nuestro redentor» que "apareció crucificado en la cruz que estaba en el monte de Buenavista junto a la ciudad de Goa». ${ }^{31} \mathrm{El}$ capítulo V está dedicado a la religión de

30. Francisco de Herrera Maldonado, Epitome historial del Reyno de la China: muerte de su reyna, madre de este Rey que hoy viue, que sucedió a treinta de marco, del mil y seiscientos y diez y siete. Sacrificios y cerimonias de su entierro. Con la descripción de aquel imperio, y la introducción. $Y$ la Introducción en el de nuestra Santa Fe católica. Por el licenciado Francisco de Herrera Maldonado Canónigo de la Santa Iglesia Real de Arbas de León, y natural de la villa de Oropesa, Marqués de Xarandilla, Conde de Beluis, Conde de Deleytosa, Señor de Cebolla, y de Villalua, \&c., Madrid, por Andrés Parra, 1620.

31. I.Descríbese el imperio de la China, sus grandezas, las calidades de sus naturales y otras curiosidades suyas /II. De la majestad del rey de la China, la guarda y habito con que se muestra en público, las cortesías de que usan aquellas gentes, los vestidos que traen con la abundancia y grandezas de aquel imperio/ III. Prosigue en la fertilidad del reino de la China, la grandiosidad de sus banquetes, solenidades y fiestas, y otras particularidades famosas/ IV. De la antigüedad de la fundición de la artillería y principio de la invención de la imprenta y cómo fueron los chinas los que inventaron estos ingenios, y después dellos se comunicaron a Europa/ V. De las setas que tienen los chinas, el número de ídolos y supersticiones. La noticia que tuvieron de nuestra fe y de la introducción del Santo Evangelio en aquel reino/VI. Del modo de escribir de los chinas. Número de sus curiosos caracteres, las ciencias que profesan y cómo las observan y aprenden/VII. De los nombres, hábito y oficios de los magistrados del reino de la China, de su gobierno, número de tribunales y jueces/VIII. Descríbese la ciudad de Pekín, corte del rey de la China/ IX. Principio de la creación del mundo y del hombre de los chinas y del origen que atribuyen a sus reyes/ X. De cómo hacen sus casamientos los chinas y de otras curiosidades suyas/ XI. De los jueces, virreyes, gobernadores y magistrados del reino de la China. Del orden que tienen en administrar justicia y en graduarse/ XII. Ritos y ceremonias sepulcrales de los chinas, cómo entierran y lloran sus difuntos y qué sacrificios les hacen/ XIII. Muerte de la reina de la China. Adorno de su cuerpo y primeros sacrificios que le hicieron/ XIV. Apercibimientos para el entierro de la reina, leyes que promulgaron los confesos y magistrados para la solemnidad grandiosa/ XV. Prosigue en las disposiciones para el entierro de la reina. El pésame que dieron al rey, su hijo, y los sacrificios que hubo aquellos días/ XVI. Descripción del carro triunfal en que se llevó el ataúd de la reina al monte de las sepulturas, prosiguen la cerimonias del entierro y la orden y acompañamiento con que salió el cuerpo del palacio/ XVII. Prosigue en las solemnidades del entierro hasta acabarse. Díceses como colocaron una memoria de la reina en un templo y de los perdones generales que hizo el rey en esta solemnidad/ XVIII. Escríbese el milagroso aparecimiento de Cristo nuestro redentor que a veintitrés de febrero de mil y seiscientos y diecinueve apareció crucificado en la cruz que estaba en el monte de Buenavista, junto a la ciudad de Goa, metrópoli de la India oriental/XIX. Prosigue el mismo glorioso aparecimiento y los milagros con que se confirmó/ XX. Trata de las rentas que en cada un ańo tiene el rey de la China, sacado de sus libros de hacienda y contaduría por el padre Miguel Rogerio, de la Compañía de Jesús. 
los chinos, o mejor, a sus «setas y supersticiones» aunque, en realidad, casi todo es un panegírico de las obras realizadas por los religiosos de la Compañía. Además de los nombres más importantes en la historia de las misiones orientales, algunos de los cuales aparecían en el catálogo de 1620, Matteo Ricci, Alessandro Valignano, Michele Ruggieri y Francisco Javier, incluye datos cuantitativos del progreso de sus trabajos en oriente: número de mártires, número de escritores y número de «religiosos, provincias y casas de la Compañía».

El tono exaltado de este capítulo evidencia la enorme admiración que sentía Herrera por los jesuitas al magnificar su tarea de evangelización en oriente. ${ }^{32}$ Es una especie de colofón a la campańa propagandística que, en cierta medida, había iniciado un año antes con la traducción de la obra que contenía información tan valiosa sobre Francisco Javier. Sin embargo, es necesario destacar que de los veinte capítulos que componen su obra solamente uno está dedicado de forma concreta a los logros de la Compañía, si bien se menciona en repetidas ocasiones a lo largo del libro, el autor intenta realizar un trabajo con carácter histórico cuyo interés principal no es la suerte de la misión sino la historia del reino de la China.

Por lo que respecta al catálogo que aparece en el Epitome, Herrera recuerda en la introducción que en otra obra que había publicado fue necesario sustentar su contenido "con autores científicos, testigos oculares y evidentes demostraciones», con el fin de acallar a los incrédulos. Podemos entender que este listado bibliográfico de 1621 tiene el mismo objetivo.

No obstante las, ahora ochenta, obras que aparecen al final del Epítome no son un reflejo de las fuentes que usa su autor, él mismo en la introducción reconoce que:

Débese grande a este discurso (fe y crédito), por ser copiado de una relación que remitió de la China un padre docto y grave de la Compañía, que se halló presente a esto que escribo, por estar en aquella gran corte de Pekín ocupado por sus superiores, por prelado de otros dignos compañeros en la misión de la China, en la expedición cristiana de aquellas gentes de Asia...

Alude a la citada De christiana expeditione de Matteo Ricci a través de Nicolas Trigault que efectivamente es su referencia principal. ${ }^{33}$

32. Sirva como ejemplo un fragmento, hablando de los logros de los hermanos de la Compañía, a quienes llama «fuertes escudos contra la herejía y acérrimos defensores de las virtudes santas.Serafines divinos que con las plumas de sus alas defienden el arca de la fe, los sacramentos de ambos testamentos. Venerables ancianos que con su elocuencia hacen música al cordero. Leones fuertes que con perpetua vigilancia hacen escolta al trono del glorioso
Salomón de rey sagrado. Caudalosos ríosque adornan y defienden la ciudad de la iglesia por cuya defensa han dado su sangre y sacrificado sus vidas...»(Epitome historial, fol. 44).

33. Roque de Oliveira (2003: 1344-1354) cita también como fuentes principales a Gaspar da Cruz, a través de González de Mendoza, la Ethiopia oriental del franciscano João dos Santos, la historia de Francisco Javier de Lucena y las cartas del padre Luis Fróis. 
En el nuevo catálogo no se percibe ningún cambio sustancial con respecto al que tratamos aquí, salvo por ejemplo la inclusión de la vida de Francisco Javier del ya mencionado Horacio Torsellini que no aparecía en el Catálogo de la Historia oriental pese a ser anterior a la de João de Lucena. Resulta significativo, respecto a la voluntad de Herrera de presentarse como un autor más de la materia oriental y no solamente como mero traductor, que las dos últimas referencias sean las de «Don Francisco de Herrera Maldonado. Historia oriental» y «De las peregrinaciones de Fernán Méndez Pinto» como si se tratara de dos obras diferentes.

Volviendo a nuestro Catálogo, las simpatías jesuitas de Herrera no impiden que, como ya he mencionado, cite las obras más significativas que autores de otras órdenes escribieron sobre China. Tres de ellas representan la contrapartida de la historia en la que los hermanos de la Compañía de Jesus empezaron a trabajar a partir de 1570 . Me refiero a la historia oriental del franciscano Marcelo Ribadeneyra de 1600 (14), a la historia de la China de Juan González de Mendoza de la orden de San Agustín (21) de 1586 y al texto del dominico Gaspar da Cruz (22) publicado en 1569. El último representa una de las más tempranas informaciones sobre China redactadas por un religioso que viajó por oriente y que desveló información real y novedosa, utilizando fuentes a las que nadie tenía acceso. Pese a ello, su obra quedó relegada al olvido aunque numerosos autores la dieron a conocer en Europa a través de copias de pasajes enteros de su Tractado. Baste como ejemplo el caso de los autores españoles: Bernardino de Escalante (63) en 1577 utilizó el texto de Cruz para componer su Discurso de la navegación; posteriormente, el agustino Juan González de Mendoza usó como una de sus principales fuentes el texto de Escalante, o lo que es lo mismo, el texto de Cruz por vía indirecta. Lo que sucedió es que el texto de Mendoza tuvo mayor fortuna y se convirtió en uno de los más populares desde el siglo XvI y durante prácticamente dos siglos, fue utilizado como lectura de referencia para las cosas de China.

Estos datos evidencian que el aparato propagandístico creado por los jesuitas opacó la labor del resto de órdenes, aunque fueron los dominicos quienes se acercaron primero a territorio chino y los agustinos quienes empezaron a recabar información desde su provincia de Filipinas y quienes difundieron, a través de Mendoza, el contenido de textos capitales para la comprensión de China hasta el XviII.

Además de las tres obras que acabo de mencionar, Herrera cita también las crónicas de San Francisco (37) de fray Diego Deza, aunque en la referencia aparece Antonio, la crónica de Santo Domingo de Serafino Razzi (35) y la historia del mismo por fray Hernando del Castillo (36).

Los textos de autores laicos están repartidos entre algunos de los cronistas más importantes de la historiografía portuguesa: encabeza el catálogo João de Barros (1), el continuador de sus Décadas Diogo de Couto (27), Fernán López de Castañeda (2), Jerónimo Osorio (3), Damián de Góis (4), Antonio de Galván (5-6), García de Resende (16), Francisco de Andrade (17) y António Pinto (61). 
Los portugueses fueron pioneros en la exploración de las costas de África y Asia. Una ingente producción textual y cartográfica sobrevino a sus navegaciones y con ella el inicio de la revelación de un mundo além-mar. Es sabido que diferentes factores impidieron que las obras que se escribieron en esta época sobrepasaran las fronteras portuguesas: el recelo de la corona con la información que obtenía y la poca difusión del portugués como lengua de cultura en las letras europeas. ${ }^{34}$ Así, entendemos que el Catálogo contenga en su mayoría autores lusos, aunque muchos de los títulos se conocieron de forma tardía o por vía interpuesta en obras españolas. Baste el citado ejemplo del texto de Gaspar da Cruz.

Un grupo de referencias está formado por textos que relatan hazañas históricas de la corona portuguesa en el proceso de conquista: hay nada menos que cuatro textos que narran los cercos de Diu, Lopo de Sousa (54), Francisco de Andrade (55), Jerónimo Corte Real (56), Diogo de Teive (57); uno para el cerco de Malaca, de Jorge de Lemos (58) y otro para el cerco de Goa, de António de Castilho (59). Entre estas obras destaca el crédito que otorga nuestro autor a fuentes épicas, y a Camóes (20) entre ellas, y los ya citados poemas épicos de Andrade y Corte Real.

Hacia el final del Catálogo, encontramos un grupo de relaciones de naufragios (65-70), tema convertido en género popular y del que se encuentran numerosos ejemplos en la literatura portuguesa de los siglos XVI y XVII. ${ }^{35}$ Es bastante apropiada la referencia en el Catálogo, si pensamos en las experiencias como náufrago que relata Mendes Pinto. Todas las obras son relatos de sucesos verídicos considerados como una expresión popular del género cronístico, cuyos autores portugueses más importantes citamos líneas arriba, una variante del género de viajes y, sobre todo, uno de los medios por el que la gente común se informaba sobre acontecimientos trágicos que ocurrían en el lejano mar, que inicialmente se publicaron en «pliegos sueltos». El naufragio de Manuel de Sousa Sepulveda junto con su esposa y sus hijos fue un hecho conocido por toda la sociedad portuguesa, como lo demuestra la composición del poema épico de Jerónimo Corte Real (65): Naufragio y lastimoso suceso da perdiçam de Manoel de Sousa Sepulveda \& dona Lianor de Sá sua mulher \& filhos...y la anónima relación del naufragio de la nave São João (69), tenida por el primer ejemplo conocido del género, versiones culta y popular del mismo tema.

Finalmente, conviene precisar que no todas las obras mencionadas por el autor circulaban necesariamente entre los lectores de la época. Es posible que, en algunos casos, ni el mismo Herrera las conociera de primera mano. Además

34. «El temor a la competencia de otros reinos, en especial de España, en un negocio que tantos réditos rendiría a la corona portuguesa, llevó a ésta a ejercer un control exhaustivo de todas las fuentes documentales sobre los nuevos territorios conquistados» en Lara Vilà
(2009: XXX) quien cita las investigaciones de J. Cortesão (1924) y (1960).

35. RemitoalbreveperocompletolibrodeGiulia Lanciani (1979) consultado en la traducción portuguesa publicada el mismo ańo que la obra original. 
del enigmático caso de Homeron historia (28) que no he podido identificar, encontramos el «Mircond en su Tarique» (44) que sigue a la referencia de Pedro Teixeira y sus relaciones de Persia y Ormuz (43).

Siglos después en la Bibliotheca Lusitana de Barbosa Machado se puede leer en la entrada correspondiente a este autor portugués la siguiente cita: ${ }^{36}$

(...) assistindo (Pedro Teixeira) neste vasto Imperio muito tempo aprendida a lingoa do Paiz intentou escrever dos Reys que o tinhaó dominado valendo-se da Chronica que escrevera Tarik Mirkond, da qual sendo muito difusa extrahio as noticias pertencentes aos Monarcas Persianos

Por tanto, la referencia procede de Teixeira, pasa a Herrera y, a través de este, es citado por Antonio de León Pinelo en el Epitome de la biblioteca oriental y occidental, náutica y geográfica, quien nos proporciona más información que el canónigo de Arbas y aclara que no tiene noticia de que exista edición traducida:

Historia de la Persia en la lengua de aquel Reyno m.s El licenciado D. Francisco de Herrera llama a esta historia Tarique...Pedro Texera la truxo i la traduxo en lengua portuguesa, i trató de imprimirla en Antuerpia, no consta que lo executasse

Por ello, se trata de una relación bibliográfica representativa y supranacional, presentada como una fuente de conocimiento múltiple. El hecho de mostrar cierta inclinación a textos escritos por jesuitas no obsta que percibamos que el autor intentaba ser exhaustivo y que, en cierta medida, realizó un catálogo heterogéneo.

\section{La composición de la biblioteca oriental}

Es posible apreciar que la gran biblioteca oriental, entendida como el conjunto de textos que circularon en los siglos XVI y XVII y crearon la imagen de oriente en Europa, es el resultado de un proceso de realimentación de unos datos que aparecen en la obra de un determinado autor, se modifican al ser utilizados por otro que no cita su fuente y vuelven a utilizarse para interpretar o, en el caso de Mendes Pinto, autorizar la misma obra de la cual surgen y con la que el público ha dejado de relacionarlos directamente. Baste un ejemplo presente en el Catálogo: Mendes Pinto habría utilizado, además de su experiencia, algunas obras portuguesas como base para la composición de su Peregrinaçam. Una de las más importantes es la del mencionado Gaspar da Cruz. ${ }^{37}$ Posteriormente, João de Lucena, entre otros, utilizó el manuscrito de Pinto para escribir su historia de la vida de Francisco Javier, y tal vez indirectamente a Cruz. Años después, Herrera 
Maldonado escribió la Apología y el Catálogo para defender la veracidad del texto y citó como autoridades a Gaspar da Cruz y al propio Lucena, en cuya obra no reconoce, al menos no explícitamente, ninguna relación con la de Mendes Pinto. Asimismo, el propio Herrera Maldonado redactó su Epitome historial y se sirvió de nuevo de la información que tomó de la Peregrinaçam, que acrecentó con datos extraídos de Maffei, en este caso, fuente confesa.

El contenido del Catálogo muestra que, en el momento de su publicación, la información de asuntos relacionados con oriente, en general, y con China, en particular, había aumentado de forma considerable a través de la composición de textos de autores religiosos. La Compañía de Jesus es la orden que consigue avances más notables en el terreno, gracias a las estrategias de acercamiento que había desarrollado desde sus inicios, por medio del aprendizaje de la lengua china y de un intento de conocer la verdadera naturaleza de sus costumbres, un trabajo que se relaciona sobre todo con los nombres de Alessandro Valignano y Matteo Ricci. A esto se sumaron los privilegios que desde inicios del siglo xvi la corona portuguesa les había concedido para acceder a territorios orientales, de forma que comenzaron a recabar información en el Estado da Índia, como lo demuestra su temprana producción epistolar. La conjunción de ambos factores se reflejó en su ingente producción textual. En el momento de la traducción de Herrera nadie que quisiera escribir sobre oriente podía sustraerse a la necesidad de usar directa o indirectamente todo este material, y así parece demostrarlo el propio autor cuando escribe el citado Epitome historial. ${ }^{38}$

Así, los textos paradigmáticos sobre Oriente permanecen inmutables en la lista de Herrera, Marco Polo es el ejemplo más claro, y junto con la información que se iba actualizando lentamente convivían una serie de tópicos que marcaron durante siglos el acercamiento entre occidente y oriente, en este caso representado por China y Japón.

Por último, la información proporcionada por Herrera, evidencia que la unificación de las coronas portuguesa y castellana, bajo el reinado de Felipe II, había facilitado el acceso a obras que antes eran apenas conocidas fuera del ám-

38. Manel Ollé (2000) establece una diferencia entre lo que denomina el paradigma ibérico y el paradigma jesuita de la imagen de China. Según el autor, en el primero confluyen «una serie de materiales provenientes de relaciones y descripciones portuguesas, basadas en testimonios directos de embajadores, prisioneros y misioneros, que tienden a reproducir y repetir los motivos y tópicos fijados por sus antecesores con una serie de percepciones castellanas fruto de las incursiones, embajadas y misiones efectuadas en Manila a partir de la década de los setenta del siglo XvI» (67-68) y que culminaría con la publicación de la Historia del gran reino de la China de Juan González de Mendoza en 1585. El segundo germina a partir de 1583 con «la primera generación de padres jesuitas que se establecieron de forma permanente en China» (73) y, según sus palabras, se caracteriza por «aumentar el ámbito de descripción geográfica al conjunto del imperio chino, penetrar en los entresijos del sistema institucional, clarificar la diversidad de corrientes de pensamiento y religiosidad existentes en China, describir los logros y limitaciones tecnológicas y eliminar algunos rastros legendarios, heredados de percepciones anteriores» (74). 
bito exclusivo de la corte lusa, sin olvidar que su difusión en el resto de Europa siempre estuvo determinada por las traducciones al castellano: Mendes Pinto es un buen ejemplo de ello.

La obra de Herrera, su traducción de la Peregrinaçam y el Catálogo que la acompaña nos dan una idea de lo que leían, o al menos de lo que debían conocer, los autores que escribían sobre oriente y los lectores interesados en el asunto, entre los que se cuenta el propio Felipe II quien, si hemos de creer al autor de la Apología, pasaba horas escuchando las aventuras del comerciante portugués. No importa si Mendes Pinto no fue fiel a la verdad. Gracias a su fama de embustero la obra fue recuperada y consiguió mantener vivo su interés hasta la época actual. Como he señalado antes, en las primeras traducciones inglesas los capítulos relacionados con la vida de Francisco Javier se omitieron, prueba de que su atractivo para el público lector se sostenía en el relato de sus trabajos en oriente y no sólo en la propaganda religiosa. La Peregrinaçam inspiró una obra de teatro, se utilizó como tema de diferentes trabajos para criticarla o elogiarla y buscar interpretaciones, que tal vez su autor nunca imaginó. Ahora posibilita que presentemos esta lista de autores cuyas obras son primordiales para comprender cómo se inició la invención de oriente desde la perspectiva occidental y la importancia de la escritura en este proceso. 


\section{Bibliografía}

Obras de referencia

Historia Oriental de las Peregrinaciones de Fernán Méndez Pinto... Traduzido [sic] de portvgues en castellano por el Licenciado Francisco de Herrera Maldonado, Canonigo de la santa Yglesia Real de Arbas... Al Excelentissimo Señor Ramiro Felipez de Guzman Señor de la Casa de Guzman, ... En Valencia, En casa de los herederos de Chrysostomo Garriz, por Bernardo Nogues, junto al molino de Rouella. Año 1645. A costa de Iuan Sonzoni, y Benito Durànd, mercaderes de libros

Viajes y crónicas de China en los Siglos de Oro. Bernardino de Escalante, Juan González de Mendoza, Fernán Méndez Pinto. Edición dirigida por María José Vega. Estudio preliminar de Lara Vilà. Ediciones y notas de Lara Vilà, Marcela Londoño e Iván Teruel. Almuzara, Córdoba, 2009

Francisco de Herrera Maldonado, Epitome historial del Reyno de la China: muerte de su reyna, madre de este Rey que hoy viue, que sucedió a treinta de março, del mil y seiscientos y diez y siete. Sacrificios y cerimonias de su entierro. Con la descripción de aquel imperio, y la introducción. Y la Introducción en el de nuestra Santa Fe católica. Por el licenciado Francisco de Herrera Maldonado Canónigo de la Santa Iglesia Real de Arbas de León, y natural de la villa de Oropesa, Marqués de Xarandilla, Conde de Beluis, Conde de Deleytosa, Señor de Cebolla, y de Villalua, \&c., Madrid, por Andrés Parra, 1620.

Peregrinaçãm de Fernam Mendez Pinto. Em que da conta de muytas e muyto estranhas cousas que vio \& ounio no reyno da China, no da Tartaria, no do Sornau, que vulgarmente se chama Siāo, no do Calaminhan, no de Pegù, no de Maruatão, \& em outros muytos reynos \& senhorios das partes Orientais, de que nestas nossas do Occidente há muyto pouca ou nenhuma noticia. E também da conta de muytos casos particulares que acontecerão assi a elle como a outras muytas pessoas. E no fim della trata breuemente de algumas cousas, \& da morte do Santo Padre mestre Francisco Xavier, única luz \& resplandor daquellas partes do Oriente, \& Reytor nellas universal da Companhia de Iesus...Em Lisboa. Por Pedro Crasbeeck. Anno 1614. A custa de Belchior de Faria...Liureyro

Peregrinaçam de Fernam Mendez Pinto, e por elle escrita: que consta de muytas e muyto estranhas cousas que vio \& ounio no reyno da China, no da Tartaria, no do Sornau, que vulgarmente se chama Siāo, no do Calaminhan, no de Pegù, no de Maruatão, \& em outros muytos reynos \& senhorios das partes Orientais, de que nestas nossas do Occidente há muyto pouca ou nenhuma noticia. E também da conta de muytos casos particulares que acontecerão assi a elle como a outras muytas pessoas. E no fim della trata breuemente de algumas cousas, \& da morte do Santo Padre mestre Francisco Xavier, unica luz \& resplandor daquellas partes do Oriente, \& Reytor nellas universal da Companhia de Iesus... ....Em Lisboa....Na Officina de António Craesbeeeck de Mello,...\& impressa â sua custa Anno de 1678 
En castellano

Historia Oriental de las Peregrinaciones de Fernán Méndez Pinto... Traduzido [sic] de portvgues en castellano por el Licenciado Francisco de Herrera Maldonado, Canonigo de la santa Yglesia Real de Arbas. Al excelenteissimo Señor Don Dvarte, Marques de Flechilla, ... Año de 1620....En Madrid. Por Tomas Iunti, Impressor del Rey nuestro señor. Impressa a costa de Manuel Rodriguez, Mercader de Libros. Vendese en su casa frontero de san Basilio en Palacio Historia Oriental de las Peregrinaciones de Fernan Mendez Pinto... A Manuel Severin de Faria, Chantre, y Canonigo de la santa Yglesia... de Euora. Año 1620... En Madrid, Por Tomas Iunti...Impressa a costa de Manuel Rodriguez

Historia Oriental de las Peregrinaciones de Fernán Méndez Pinto... Traduzido [sic] de portvgues en castellano por el Licenciado Francisco de Herrera Maldonado, Canonigo de la santa Yglesia Real de Arbas. Al excelenteissimo Señor Don Dvarte, Marques de Flechilla, ... En Madrid, Por Diego Flamenco, Año de 1627. Impressa a costa de Iuan del Casar, Mercader de Libros. Vendese en su casa frontero de san Basilio, y en Palacio

Historia Oriental de las Peregrinaciones de Fernán Méndez Pinto... Traduzido [sic] de portvgues en castellano por el Licenciado Francisco de Herrera Maldonado, Canonigo de la santa Yglesia Real de Arbas... Al Señor don Antonio de Vrvtia y Aguirre, ...En Madrid por Melchor Sanchez. Año de 1664. A costa de Mateo de la Bastida Mercader de Libros, vendese en su casa frontero de las gradas de San Felipe

Historia Oriental de las Peregrinaciones de Fernán Méndez Pinto... Traduzido [sic] de portvgues en castellano por el Licenciado Francisco de Herrera Maldonado, Canonigo de la santa Yglesia Real de Arbas...En Madrid por Melchor Sanchez. Año de 1666. A costa de Mateo de la Bastida Mercader de Libros,...

Primeras traducciones

Les Voyages advantvrevx de Fernand Mendez Pinto. Fidelement tradvicts de Portugais en François par le Sieur Bernard Figvier Gentil-home Portugais. Et dediez a Monseignevr Le Cardinal de Richeliev...A Paris, Chez Mathvrin Henavlt ruë Clopin, deuant le petir Nauarre: \& à sa boutique en la Cour du Palais, à costé de la Chappelle sainct Michel, proche la fontaine. M.DC.XXVIII

De wonderlyke Reizen van Fernando Mendez Pinto;... Nieuwelijks door J.H. Glazemaker vertaalt; en met cierlijke Kopere Platen verciert. t'Amsterdam, Voor Jan Rieuwertsz en Jan Hendrisz Boekverkopers. 1652

The Voyages and Adventures of Fernand Mendez Pinto, a Portugal: ... Written Originally by himself in the Portugal Tongue, and Dedicated to the Majesty of Philip King of Spain. Done into English by H. C. Gent. London, Printed by J. Macock, for Henry Cripps, and Lodowick Lloyd, and are to be sold at their shop in Popes head Alley neer Lumbar-Street. 1653

Wunderliche und Mercwürdige Reisen Ferdinandi Mendez Pinto, ... Nun erst ins Hochteutsche übersetzet und mit unterschiedlichen Kuperstükken gezierct. Am- 
sterdam. Bey Henrich und Dietrich Boom, Buchhändlern, Im Jahr Christi 1671

António de León Pinelo, Epitome de la biblioteca Oriental i Occidental, Nautica i Geográfica. Al excelentísimo señor don Ramiro Núñez Pérez Felipe de Guzmán. Señor de la casa de Guzmán, duque de Medina de las Torres, marqués de Toral y Monasterio ... / por el licenciadoAntonio de León, relator del supremo y real Consejo de las Indias ... En Madrid por Juan González, 1629.

Diogo Barbosa Machado, Bibliotheca lusitana, Coimbra: Atlântida, 1965-1967, 4 vv. Facsím.

Aires, Cristovão, Fernão Mendes Pinto, Subsidios para a sua Biografia e para o estudo da sua Obra, Lisboa, 1904

—, Fernão Mendes Pinto e o Japão. Discussão. Informações Novas. Memória apresentada à Academia Real das Sciencias de Lisboa, Lisboa, 1906

Abranches, Pinto J. y Okamoto, Ioxitomo, «Mendes Pinto e o descobrimento do Japão» en Boletim da Sociedade Luso-Japonesa, 1 (1929) 78-84.

Almeida, Fernando António "Alguma biografia de Fernáo Mendes Pinto" en Peregrinação e Cartas, Fernão Ribeiro de Mello, Lisboa, Ed. Afrodite, 1989.

Boxer, Charles, The Tragic History of the Sea, 1589-1622. Narratives of the shipwrecks of the Portuguese East-Indiamen, São Tomé (1589), Santo Alberto (1593), São João Baptista (1622), and the journeys of the survivors in South East Africa. Edited from the original Portuguese by -, Cambridge, 1959

-, Further Selections from the Tragic History of the Sea, 1559-1565. Narratives of the shipwrecks of the Portuguese East - Indiamen Aguia and Garça (1559), São Paulo (1561), and the misadventures of the Brazil-ship Santo António (1565). Translated and edited from the original Portuguese by —, Cambridge, 1968. Ta

Catz, Rebecca, A Sátira Social de Fernão Mendes Pinto. Análise Crítica da Peregrinação, Col. «Estudos e Ensaios», Lisboa, Prelo Editora, 1978.

-, The travels of Mendes Pinto, Edited and Translated by Rebecca D. Catz, The University of Chicago Press, 1989.

D'Intino, Raffaella, Enformação das cousas da China : textos do século XVI / introdução e leitura de Raffaella D'Intino, Lisboa, Impr. Nacional Casa-daMoeda, 1989.

Collis, Maurice, The Grand Peregrination, Lonndres, Faber and Faber, 1949.

Cortesão, Armando, "Japão" en Acta universitatis conimbrigensis. Esparsos I, Coimbra, Universidade de Coimbra, 1975.

Faria, Francisco Leite de, As muitas ediçóes da Peregrinaçam de Fernão Mendes Pinto, Lisboa, Academia portuguesa da história, 1992.

Freitas, Jordão de, Subsídios para a Bibliografia portuguesa e para a biografia de Fernão Mendes Pinto, Coimbra, 1905.

LANCIANI, Giulia, Os relatos de naufrágios na literatura portuguesa dos séculos XVI $e$ XVII. Traducción del italiano por Manuel Simóes (1979), Venda Nova (Amadora), Instituto de cultura portuguesa, 1979 . 
Ollé, Manuel, La invención de China. Percepciones y estrategias flipinas respecto a China durante el siglo XVI, Wiesbaden, Harrassowitz Verlag, 2000.

Pinto Correia, João David, Autobiografia e aventura na literatura de viagens: A Peregrinação / de Fernão Mendes Pinto; apresentação crítica, selecção, resumos, glossário e sugestóes para análise literária de João David Pinto Correia, Comunicação, Lisboa, 1979.

Rienstra, Howard (ed.), Jesuits Letters from China 1583-1584, traducción de Avvisi della Cina dell'ottantatre et dell'ottantaquatro, University of Minesota Press, 1986.

Saraiva, António José, Fernão Mendes Pinto, col. «Saber», Lisboa, Publicaciones Europa-América, 1958.

Saraiva, António José, Fernão Mendes Pinto, ou a Sátira Picaresca da Ideologia senhorial, Lisboa, Jornal del Foro, 1958.

Schurhammer, Georg, "Uns documentos inéditos sobre Fernão Mendes Pinto", Revista de História, vol. 13, (1924) 81-88.

VILÀ, Lara, «Viajes y crónicas de oriente en el siglo de los descubrimientos» en Viajes y crónicas de China, María José Vega ed., Córdoba, Almuzara, 2009. 